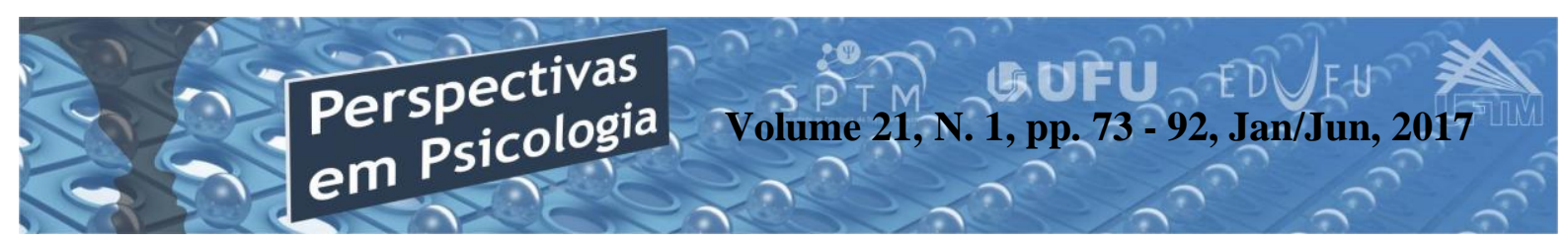

\title{
FORMAÇÃO DO PSICÓLOGO HUMANISTA: REVISÃO SISTEMÁTICA
}

\author{
Paulo Coelho Castelo Branco \\ Gabriel Nery Matos \\ Alexandre Gregório Silva Sampaio \\ Bruna Rocha Amaral \\ (Universidade Federal da Bahia - UFBA)
}

\begin{abstract}
Resumo
Analisamos artigos sobre a formação do psicólogo humanista nas bases SciELO e PePSIC, segundo uma revisão sistemática. Catalogamos oito artigos conforme título, autor(es), base de dados, periódico, ano, área, tipo de estudo, objetivo e resultado do estudo. Os resultados demonstraram: hegemonia de produções em um periódico humanista; predominância de publicações no PePSIC; concentração de discussões clínicas; tendência para utilizar referenciais humanistas-fenomenológicos-existenciais em pesquisas empíricas e teóricas. Discutimos eixos temáticos relacionados: a formação técnica e a formação experiencial; à clínica como um lugar de (trans)formação pessoal e social; à horizontalidade formadorformando; ao plantão psicológico e a versão de sentido como recursos formativos. Concluímos que o tema carece de pesquisas empíricas e teóricas, sobretudo no âmbito extraacadêmico.
\end{abstract}

Palavras-chave: Fenomenologia; formação do psicólogo; psicologia humanista; revisão de literatura.

\section{Abstract \\ Humanistic psychologist formation: systematic review}

We analyze articles concerning the Humanist Psychology formation in SciELO and PePSIC, bases, according a systematic review. We cataloged eight articles conforming to title, author(s), database, periodicity, year, area, type of study, goals and results of the study. The results show: hegemony of productions in a humanistic journal; predominance of publications in PePSIC; concentration of clinical discussions; tendency of using humanisticphenomenological-existential references in empirical and theoretical researches. We discussed thematic axis related to: the technical formation and the experiential formation; the clinic as a personal and social (trans)formation place; the horizontality trainer-trainee; the psychological duty and the sense version as formatives resources. We concluded that the subject lack empirical and theory researches, even more in the extra academic environment.

Keywords: Humanistic psychology; literature review; phenomenology; psychologist education. 


\section{Introdução}

A Psicologia Humanista é uma perspectiva de ciência que surgiu, na década de 1960, composta por diversas abordagens clínicas, educacionais, organizacionais e de pesquisas empíricas. Segundo o site oficial da American Psychological Association (APA), na Divisão 32, onde está alocada a Sociedade de Psicologia Humanista (Society for Humanistic Psychology, 2017, n/p), esta “[...] reconhece a riqueza da experiência humana, suas basesincluemo humanismofilosófico, o existencialismoe a fenomenologia. A Sociedadepretende contribuir paraa psicoterapia, educação, teoria/filosofia, pesquisa, organização, gestão, responsabilidade social e mudança" (tradução nossa). Destarte, ao convencionar a experiência humana e sua ampliação como objeto de estudo e intervenção, a Psicologia Humanista estabelece um corpo de abordagens e perspectivas metodológicas de pesquisas e intervenções.

Das diversas abordagens humanistas, consideramos as mais conhecidas à Abordagem Centrada na Pessoa (ACP) de Carl Rogers e à GestaltTerapia de Fritz Perls, conquanto existam outras perspectivas como, por exemplo, à Psicologia Existencial de Rollo May e à
Focalização de Eugene Gendlin. Entretanto, há outras abordagens humanistas de pesquisas empíricas, que não são necessariamente psicoterapêuticas - por exemplo, as vertentes fenomenológicas-empiricas de Adrian van Kaam e Amedeo Giorgi, e a perspectiva heurística-existencial de Clark Moustakas. Em relação à Logoterapia, esta se configurou como uma abordagem humanista mais pelo contraponto proficiente que Viktor Frankl apontou ao humanismo estadunidense do que por sua total adesão institucional ao movimento (Taylor \& Martin, 2001).

Muitos expoentes humanistas se interessaram pela formação dos seus estudantes. Por exemplo, Rogers (1977, 1983) montou um programa de treinamento das atitudes clínicas centradas no cliente e, posteriormente, desenvolveu um modelo de formação grupal (os chamados workshops) para capacitar facilitadores da Abordagem Centrada na Pessoa. Com o intuito de formar gestaltterapeutas, Perls fundou diversos Institutos de Gestalt, que disseminamsua tradição até os dias atuais em várias localidades do Mundo (Helou, 2015). Assim, a tradição humanista está presente em diversos centros formativos universitários e extrauniversitários. 
Considerando que o tema da formação do psicólogo tem se desenvolvido, no Brasil, como um extenso campo de pesquisas, discussões e reflexões (Yamamoto \& Costa, 2010), percebemos que o cenário humanista nacional não está apartado desse contexto ao estudar experiências de formação em seus estudantes. Com efeito, este estudo objetiva analisar o conhecimento produzido em relação à formação de psicólogos humanistas no Brasil. A pergunta que norteou todo o processo de pesquisa foi: que conhecimento sobre a formação do psicólogo humanista foi produzido em periódicos brasileiros? Destarte, inicialmente, apresentamos o plano metodológico que possibilitou o acesso a artigos que estudam a formação do psicólogo humanista. Em seguida, organizamos os resultados do que foi coletado para, finalmente, discutirmos quais eixos temáticos são concernentes à formação do psicológico humanista nos estudos compilados.

\section{Método}

Para cumprir com o objetivo proposto elegemos a revisão sistemática de literatura como método de pesquisa. Assim, empregamos os aportes metodológicos de Costa e Zoltowski (2014) como modo de busca e organização de dados referentes às produções ligadas a formação do psicólogo humanista que circulam em duas bibliotecas virtuais, o Scientific Electronic Library Online (SciELO) e o Portal de Periódicos Eletrônicos em Psicologia (PePSIC).

O motivo que nos levou a utilizar o SciELO foi o fato de ele ser considerado, pela United Nations, Educational, Scientificand Cultural Organization (UNESCO), como o maior provedor de periódicos indexados de acesso aberto do mundo(Packer, Cop, Luccisano, Ramalho \& Spinak, 2014). O SciELO estabelece, ainda, uma parceria com o BIREME Centro Latino-Americano e do Caribe de Informação em Ciências da Saúde. O PePSIC foi escolhido por utilizar o mesmo sistema e método de busca do SciELO. O PePSIC é uma fonte ligada à Biblioteca Virtual em Saúde - Psicologia da União Latino-Americana de Entidades de Psicologia (BVS-Psi ULAPSI), que divulga somente periódicos e artigos em Psicologia. Em razão desses fatores, ponderamos que essas duas bibliotecas atenderiam melhor as necessidades de nossa pesquisa, pois encontramos em ambas uma amplitude e representatividade na circulação de artigos científicos relacionados à Psicologia Humanista brasileira.

Nas duas bases de dados realizamos um levantamento das palavras-chave 
representativas são tema proposto. No índice de assuntos do SciELO foram elencados os seguintes descritores (total de 15): Psicologia Humanista, Psicologia Humanística, Psicologia Fenomenológica, Psicologia Fenomenológica Existencial, Psicologia Fenomenológico Existencial, Psicologia Existencial, Terapia Centrada na Pessoa, Terapia Centrada no Cliente, Carl Rogers, Terapia Não Diretiva, Logoterapia, Viktor Frankl, GestaltTerapia, Fritz Perls, Plantão Psicológico. No mesmo índice do PePSIC encontramos este descritores (total de 17): Psicologia Humanista, Psicologia Humanística, Psicologia Fenomenológica, Psicologia Fenomenológica Existencial, Psicologia Fenomenológico Existencial, Psicologia Fenomenológica Existencialista, Psicologia Existencial, Terapia Centrada na Pessoa, Terapia Centrada no Cliente, Carl Rogers, Terapia Não Diretiva, Logoterapia, Viktor Frank1, Gestalt-Terapia, Gestalt Terapia, Fritz Perls, Plantão Psicológico. Ressaltamos que os descritores em inglês (por exemplo, Gestalt-Therapy) não foram incluídos na busca, pois constatamos que eles apresentavam os mesmos termos em português, gerando resultados iguais.

A despeito dessa busca, percebemos a necessidade de uma contemplação mais abrangente sobre o tema da formação do psicólogo humanista.
Por isso, optamos por acrescentar mais descritores vinculados ao campo da formação do psicólogo no Brasil. Logo, acrescentamos os termos Formação do Psicólogo e Formação em Psicologia, no SciELO; e Formação do Psicólogo, Formação em Psicologia e Formação Clínica, no PePSIC.

Salientamos que não utilizamos o recurso de cruzamento de termos, com o intuito de buscar detalhadamente as informações nos artigos gerados em cada descritor investigado. Os artigos foram lidos conforme o seu título, resumo e palavras-chave. Como critério básico de inclusão, elegemos todos os artigos que abordaram o tema da formação de psicólogos humanistas, em seus afluentes fenomenológicos e existenciais, independentemente de sua abordagem interventiva e de pesquisa. Neste caso, os textos incluídos foram lidos na integra. Excluímos as produções publicadas em periódicos estrangeiros e lançados em 2017, pois muitos periódicos ainda estão organizando os volumes do ano corrente, não possibilitando uma visão geral do que foi produzido durante $\mathrm{o}$ ano. Artigos presentes em mais de uma base de dados ou descritores foram computados somente uma vez, descartando-se os repetidos. A coleta dos dados bibliográficos aconteceu entre os meses de dezembro de 2016 e 
janeiro de 2017, por quatro juízes independentes. $\mathrm{O}$ recorte temporal foi estabelecido de1997, ano do artigo mais antigo encontrado, até 2015, ano do último minutado.

A catalogação das produções obtidas foi realizada conforme as seguintes categorias: título; nome do(s) autor(es); base de dados; periódico; ano de publicação;área de discussão; tipo de estudo(teórico, empírico ou relato de experiência); objetivos e resultados. Nas produções empíricas recortamos os procedimentos de coleta e análise dos dados; nos artigos teóricos e relatos de experiência especificamos o referencial da reflexão. Todas as discordâncias ocorridas durante $o$ processo de coleta foram debatidas e resolvidas por consenso entre os pesquisadores.

Destarte, a Figura 1, expressa a seguir, apresenta o fluxograma do processo de coleta de dados e tem como resultado o número final $(\mathrm{N})$ dos artigos encontrados, os quais constituíram o material analisado para pensar os temas que permeiam a formação do psicólogo humanista brasileiro.

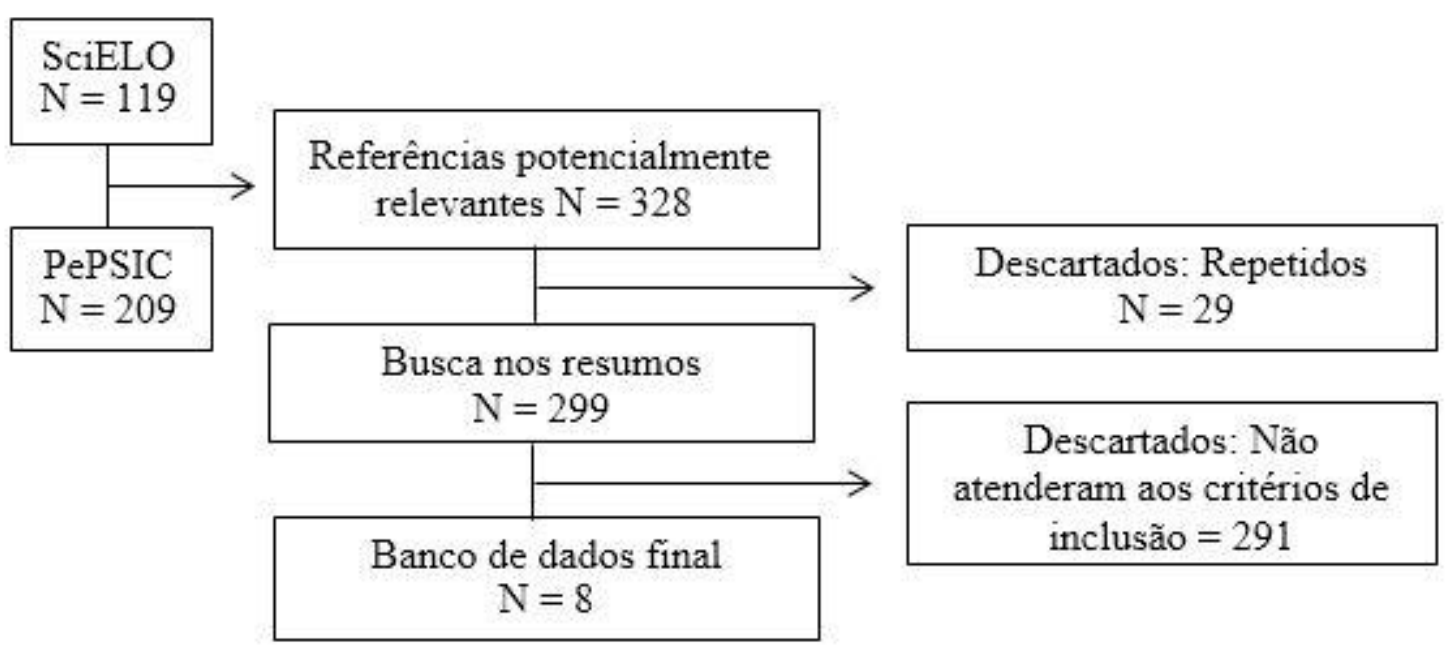

Figura 1 - Estratégia de busca.

Fonte: elaboração própria dos autores.

\section{Resultados}

Apresentamos, neste tópico, os resultados das catalogações dos oitos artigos minutados conforme o método da revisão sistemática. Expomos em seguida, na Tabela 1, uma ordem inicial de organização que permite uma visão geral das produções levantadas. 
Tabela 1

Distribuição dos oito artigos compilados

\begin{tabular}{|c|c|c|c|c|}
\hline Título & Ano & $\begin{array}{c}\text { Base de } \\
\text { Dados }\end{array}$ & Periódico & $\begin{array}{c}\text { Área de } \\
\text { Discussão }\end{array}$ \\
\hline $\begin{array}{l}\text { Psicólogos em formação: vivências e } \\
\text { demandas em plantão psicológico. }\end{array}$ & 2007 & SciELO & $\begin{array}{l}\text { Psicologia: } \\
\text { Ciência e } \\
\text { Profissão }\end{array}$ & $\begin{array}{l}\text { Formação } \\
\text { Clínica }\end{array}$ \\
\hline $\begin{array}{l}\text { Psicologia e atenção básica: vivências } \\
\text { de estagiários na Estratégia de Saúde da } \\
\text { Família. }\end{array}$ & 2009 & SciELO & $\begin{array}{l}\text { Ciência \& } \\
\text { Saúde } \\
\text { Coletiva }\end{array}$ & Saúde \\
\hline $\begin{array}{l}\text { A Gestalt-Terapia na universidade: da } \\
\text { f(ô)rma à boa forma. }\end{array}$ & 2009 & PePSIC & $\begin{array}{l}\text { Estudos e } \\
\text { Pesquisas } \\
\quad \text { em } \\
\text { Psicologia }\end{array}$ & $\begin{array}{l}\text { Formação } \\
\text { Clínica }\end{array}$ \\
\hline $\begin{array}{l}\text { Reflexões fenomenológicas sobre a } \\
\text { experiência de estágio e supervisão } \\
\text { clínica em um serviço de psicologia } \\
\text { aplicada universitário. }\end{array}$ & 2010 & PePSIC & $\begin{array}{l}\text { Revista da } \\
\text { Abordagem } \\
\text { Gestáltica }\end{array}$ & $\begin{array}{l}\text { Formação } \\
\text { Clínica }\end{array}$ \\
\hline $\begin{array}{l}\text { "Versando sentidos" sobre o processo } \\
\text { da aprendizagem em Gestalt-Terapia. }\end{array}$ & 2012 & PePSIC & $\begin{array}{l}\text { Revista da } \\
\text { Abordagem } \\
\text { Gestáltica }\end{array}$ & $\begin{array}{c}\text { Atuação } \\
\text { Educacional }\end{array}$ \\
\hline $\begin{array}{l}\text { Formação do psicólogo clínico na } \\
\text { perspectiva fenomenológico-existencial: } \\
\text { dilemas e desafios em tempos de } \\
\text { técnicas. }\end{array}$ & 2013 & PePSIC & $\begin{array}{l}\text { Revista da } \\
\text { Abordagem } \\
\text { Gestáltica }\end{array}$ & $\begin{array}{l}\text { Formação } \\
\text { Clínica }\end{array}$ \\
\hline Plantão Psicológico: ficções e reflexões. & 2015 & SciELO & $\begin{array}{l}\text { Psicologia: } \\
\text { Ciência e } \\
\text { Profissão }\end{array}$ & $\begin{array}{l}\text { Formação } \\
\text { Clínica }\end{array}$ \\
\hline $\begin{array}{l}\text { A ética do cuidado e o encontro com o } \\
\text { outro no contexto de uma clínica-escola } \\
\text { em Fortaleza. }\end{array}$ & 2015 & PePSIC & $\begin{array}{l}\text { Revista da } \\
\text { Abordagem } \\
\text { Gestáltica }\end{array}$ & $\begin{array}{l}\text { Formação } \\
\text { Clínica }\end{array}$ \\
\hline
\end{tabular}

Fonte: elaboração própria dos autores.

Os dados compilados demonstram uma concentração de 50,00\% (n=4) de publicações na Revista da Abordagem Gestáltica - Phenomenological Studies. Entendemos que isso ocorre em razão deste periódico ter uma orientação editorial focada para publicar artigos com referenciais humanistas, fenomenológicos e existenciais. Atentamos, ainda, para uma predominância de artigos dispostos na base 


\section{FORMAÇÃO DO PSICÓLOGO HUMANISTA: REVISÃO SISTEMÁTICA}

PePSIC (n=5), em decorrência deste discussões decorrentes da clínica (Taylor congregar, especificamente, periódicos de \& Martin, 2001), a despeito de suas Psicologia. ramificações para outros campos como,

Observamos que das áreas de por exemplo, os da Saúde e da Educação. discussão o campo da formação clínica é Com o intuito de pormenorizar os predominante $(\mathrm{n}=6 ; 75,00 \%)$ nos artigos conteúdos das produções minutadas, coletados. Esse dado exprime uma tradição situamos na Tabela 2, apresentada a seguir, formativa na Psicologia Humanista, dado os objetivos e os achados (resultados) das que esta ciência nasceu a partir de pesquisas proposta pelos seus autores. 
Tabela 2

Organização dos objetivos e achados das pesquisas

\begin{tabular}{|c|c|}
\hline Autores & $\begin{array}{l}\text { Objetivos e achados da pesquisa } \\
\end{array}$ \\
\hline $\begin{array}{l}\text { Paparelli e } \\
\text { Nogueira- } \\
\text { Martins (2007) }\end{array}$ & $\begin{array}{l}\text { Refletem a formação de plantonistas segundo suas experiências. } \\
\text { Demonstram a necessidade de estimular a discussão sobre o papel da } \\
\text { universidade na gestação dos saberes, principalmente sobre a função } \\
\text { social das clínicas-escola na constituição de práticas mais humanizadas. }\end{array}$ \\
\hline $\begin{array}{c}\text { Sousa e Cury } \\
(2009)\end{array}$ & $\begin{array}{l}\text { Pesquisam experiências de estagiários em Psicologia na área da } \\
\text { Saúde/Clínica na atenção básica em Saúde Pública. Sugerem que a } \\
\text { implantação de uma forma alternativa (humanista) de modelo de saúde } \\
\text { na atenção básica afeta o modo de subjetivar, analisar, agir e viver dos } \\
\text { estagiários que passaram por tal processo formativo. }\end{array}$ \\
\hline Soares (2009) & $\begin{array}{l}\text { Discute as características do trabalho de supervisão em Gestalt-Terapia } \\
\text { no Serviço de Psicologia Aplicada. Destaca que o supervisor serve de } \\
\text { acompanhante formativo, numa passagem que é feita através de sentidos } \\
\text { e afetos, de acordo com cada momento do estagiário. Argumenta uma } \\
\text { subversão ao modelo instrumentalizado e padrão de supervisão clássica. }\end{array}$ \\
\hline
\end{tabular}

Sá, Azevedo

Refletem as dificuldades da formação clínica fenomenológicaJúnior e Leite (2010) existencial, a partir de situações que envolvem o estágio clínico. O impasse entre os paradigmas teóricos e as identidades profissionais é essencial para um redimensionamento do lugar das teorias e técnicas na prática do cuidado clínico.

Maia, Freire e

Exploram o processo de facilitação da aprendizagem em Gestalt-Terapia Oliveira (2012) no ambiente acadêmico. Atribuem a Gestalt-Terapia uma maneira compreensiva de abordar o outro, defendendo uma prática docente que possibilite ao estudante uma consciência da alteridade em si e no outro.

Dutra (2013)

Desenvolve uma reflexão sobre formação do psicólogo clínico na perspectiva fenomenológica-existencial. $\mathrm{O}$ exercício ontológico de serenidade e certeza de poder-ser é uma via formativa para tal formação.

Carvalho,

Alves, Indagam a prática psicoterapêutica na graduação, considerando-a como Passos, Lopes, uma profissão da saúde. O estagiário não deve enquadrar o cliente em Holanda e um tratamento pré-determinado, mas singularizá-lo atentando para Moreira (2015) conhecimentos objetivos e os processos de adoecimento e sofrimento.

Breschiglarie Tematizam uma experiencia de plantão psicológico e consequentes Breschigliari e reflexões sobre o sentido dessa modalidade, fronteiriça a psicoterapia. Jafelice (2015) Apresentam um relato ficcional sobre experiências vividas no plantão psicológico. Frisam a necessidade de não suplantar o vivido na clínica.

Fonte: elaboração própria dos autores. 
No que concerne aos tipos de estudos levantados, notamos uma distribuição de quatro estudos empíricos $(50,00 \%)$, três teóricos $(37,50 \%)$ e um relato de experiência $(12,50 \%)$. Ao aprofundar como as pesquisas empíricas sobre a formação do psicólogo humanista ocorreram, elaboramos a Tabela 3, expressa em seguida, que organiza os procedimentos de coleta e análise de dados utilizados nas pesquisas.

Tabela 3

Organização metodológica das pesquisas empíricas

\begin{tabular}{|c|c|c|c|}
\hline $\begin{array}{l}\text { Método de } \\
\text { Coleta }\end{array}$ & Método de Análise & $\mathbf{N}$ & $\%$ \\
\hline Grupo focal & Análise temática & 1 & 25,00 \\
\hline $\begin{array}{l}\text { Diário de campo } \\
\text { e entrevista } \\
\text { semi-estruturada }\end{array}$ & Analise fenomenológica empírica de Amedeo Giorgi & 1 & 25,00 \\
\hline $\begin{array}{l}\text { Versão de } \\
\text { sentidos }\end{array}$ & $\begin{array}{l}\text { A partir dos relatos da versão de sentidos foi feita uma } \\
\text { análise à luz das teorias de Martin Buber sobre educação e } \\
\text { filosofia dialógica, dialogando com a filosofia da alteridade } \\
\text { de Emmanuel Lévinas }\end{array}$ & 1 & 25,00 \\
\hline Entrevista aberta & $\begin{array}{l}\text { Analise fenomenológica interpretativa de influência } \\
\text { gadameriana }\end{array}$ & 1 & 25,00 \\
\hline & Total & 4 & 100 \\
\hline
\end{tabular}

Fonte: elaboração própria dos autores.

Na tabela exposta, observamos que os referenciais fenomenológicos e existenciais, em suas perspectivas empíricas e filosóficas, constituem uma lente analítica dos dados coletados. Em relação aos artigos teóricos e ao relato de experiência, apresentamos uma organização sobre as suas reflexões, a seguir, na Tabela 4. 
Tabela 4

Reflexões presentes no relato de experiência e nos artigos teóricos

\begin{tabular}{cccc}
\hline $\begin{array}{c}\text { Tipo de } \\
\text { Estudo }\end{array}$ & Reflexão & N & \% \\
\hline $\begin{array}{c}\text { Relato de } \\
\text { Experiência }\end{array}$ & $\begin{array}{c}\text { Articula a vivência clínica com reflexões teóricas no âmbito } \\
\text { da Abordagem Centrada na Pessoa e da fenomenologia- } \\
\text { existencial. }\end{array}$ & 1 & 25,00 \\
Teórico & $\begin{array}{c}\text { Raciocínio clínico baseado na Gestalt-terapia para pensar a } \\
\text { disponibilidade do estagiário para aceitar sua condição de } \\
\text { "não pronto". }\end{array}$ & 1 & 25,00 \\
Teórico & $\begin{array}{c}\text { Utiliza a ontologia heideggeriana para refletir a prática } \\
\text { clínica no decorrer da formação do estagiário, em uma crítica } \\
\text { às demandas de respostas imediatas. }\end{array}$ & 1 & 25,00 \\
& Reflete as dificuldades específicas da formação clínica em \\
uma perspectiva fenomenológica-existencial. & 1 & 25,00 \\
& Total & 4 & 100 \\
\hline
\end{tabular}

Fonte: elaboração própria dos autores.

Notamos, portanto, que nos artigos analisados os referenciais fenomenológicos e existenciais, da ACP e da Gestalt-Terapia são as fontes reflexivas para pensar os elementos concernentes à formação humanista na clínica. Passemos a discutir os eixos temáticos relacionados à formação do psicólogo humanista.

\section{Discussão}

Neste tópico pretendemos, com base na leitura das oito produções reunidas, desenvolver uma reflexão acerca dos elementos formativos do psicólogo humanista, segundo quatro eixos temáticos obtidos das articulações que fizemos. Apresentamos cada eixo na sequência.

Tensão entre formação técnica e formação experiencial

A formação em Psicologia, em suas diretrizes e pressupostos, tem como intenção primordial desenvolver técnicas e habilidades que permitam ao futuro profissional uma capacitação para lidar com as demandas da população. Considerando que a perspectiva positivista de produção de ciência é hegemônica no campo da formação em Psicologia, muitos psicólogos humanistas questionam as 
implicações que esse tipo de formação produz na desconsideração da subjetividade e da experiência no processo de formativo para lidar com pessoas.

Ao se distanciar de um modelo formativo médico tradicional, a prática do psicólogo humanista tem emergido a partir de configurações relacionais mais humanas e horizontais, que criticam as neutralidades profissionais e os reducionismos psicopatológicos (Carvalho e outros, 2015). Assim, torna-se necessário compreender em que sentido o processo de formação pode se tornar um norteador indispensável à construção de um aparato interventivo,que ao mesmo tempo forma o estudante e o conscientiza da importância de focar a experiência do outro, de si e da realidade social que abrange a relação.

Com base nos artigos encontrados, uma das discussões centrais relacionadas à formação humanista é estabelecida pelo conflito entre uma linha tecnicista, vista como tradicional e preponderante no meio universitário, e um formato experiencial, condizente com as perspectivas humanistas, fenomenológicas e existenciais (Soares, 2009; Dutra, 2013; Maia, Freire \& Oliveira, 2012; Carvalho e outros, 2015).

A perspectiva tecnicista, por um lado, é vista como produtora de práticas que emolduram a formação do estudante em uma fixação explicativa e técnica, com pouca flexibilidade na articulação entre a experiência do estudante e o seu contexto formativo. Ocorre uma produção em massa de psicólogos técnicos pouco atentos as suas experiências formadoras e as suas singularidades como pessoa. A visada experiencial, em contrapartida, atenta para uma proposição fluída do processo de se formar. Dessa maneira, enfoca-se o acesso à subjetividade dos estudantes para possibilitar uma formação mais coerente as suas experiências (Soares, 2009; Maia e outros, 2012; Dutra, 2013; Carvalho e outros, 2015).

Com efeito, a perspectiva experiencial se configura como uma reorganização em relação ao modo como o profissional humanista irá se posicionar frente às demandas, uma vez que a sua formação é um meio de transformação que acontece através da experiência. Em outras palavras, tal formação seria um abandono das fôrmas curriculares que atuam como agente inibidor das potencialidades da pessoa, dando lugar a descobertas de atuação que são criadas e recriadas a partir da experiência de cada um, saindo da lógica técnica de reprodutores de intervenções em série (Soares, 2009). A formação humanista, portanto, compreende o termo "formado" não no sentido de algo pronto e acabado, mas inacabado e em constante processo de contato com a experiência (Dutra, 2013). 
A clínica como ocasião de (trans)formação pessoal e social pelo sentido e a alteridade

O contexto clínico tem sido atravessado pela necessidade em obter respostas imediatas e soluções rápidas para os problemas humanos, mediante uma lógica pré-estabelecida do mercado de consumo. Nesse sentido, muitas práticas clínicas têm se convertido em um fazer técnico e mecanicista que subjuga ou desconsidera a dimensão da experiência subjetiva dos processos de sofrimento psíquico e a dimensão social que o acompanha, centrando-se no sintoma e não no sujeito. Para Dutra (2013),

A técnica, no sentido moderno e que tem como princípio a instrumentalidade, tem sido considerada a solução também para as doenças da alma e para os mal-estares que acometem o homem contemporâneo. No entanto, é importante pensar que esse homem, constituído e constituinte de um mundo no qual prevalece a cultura do narcisismo e do consumo, vê-se perdido, desenraizado e em busca de um sentido para sua existência (Dutra, 2013, p. 206).
A Psicologia, em sua busca por afirmação de cientificidade, tem adotado critérios oriundos do paradigma positivista, que busca por uma replicação e generalidade de suas intervenções, criando uma clínica afastada dos processos singulares de cada pessoa. Dutra (2013) questiona a radicalidade de tal posicionamento ao afirmar que nem sempre essa posição científica é possível e exeqüível. A dimensão do sujeito pertence a uma postura de abertura ao imprevisível na relação e no contato com o outro, com vistas à ampliação e produção de novos sentidos para a experiência. Nas palavras da mencionada autora:

[...] Isso ocorre porque estamos lidando com a complexidade de um ser que atribui sentidos à sua existência e, portanto, é singular. Assim, haverá, sempre, algo que ficará de fora do representado, o imponderável, aquilo que não se prevê e nem se deixa controlar; melhor dizendo, algo não dito e cujos sentidos se desvelam à medida que somos-nomundo. Refiro-me a algo que escapa às verdades estabelecidas, aquelas originadas de uma perspectiva que coisifica o homem e desconsidera a sua capacidade de ser e existir num mundo de possibilidades e indeterminação (Dutra, 2013, p. 207). 
Independentemente do contexto clínico e da perspectiva teórica em que o psicólogo irá atuar, a experiência de contato com outro que lhe é estranho estará sempre presente e pulsante na relação, demandando do profissional em formação uma postura compreensiva acerca dos fenômenos que estão presentes em suas práticas clínicas, a partir dos sentidos que compõe essa experiência. Aos humanistas em formação, torna-se importante estar aberto aos sentidos que compõem e constituem o outro na relação, pois "[...] é na multiplicidade que nos constitui, que se torna possível a abertura às distintas singularidades e alteridades do outro. O que seria isso senão a abertura ao velamento-desvelamento que constitui o modo-de-ser-humano?" (Dutra, 2013, p. 208). O movimento de se colocar disponível à alteridade, bem como se dispor à dimensão do cuidado com o outro é essencial para o fazer clínico humanista e fenomenológico. Carvalho e outros, (2015), com base em Heidegger, afirma que, como uma dimensão ontológica, o cuidado é originariamente compreendido como "cura", sendo esta constituinte da existência humana. Cuidar é mais que um ato, pois engloba um momento de atenção, zelo e desvelo; representa uma atitude de ocupação, pré-ocupação, responsabilização e envolvimento afetivo-ético com o outro.
A formação humanística, também, ancora-se na relação/tensão do serviço clínico tradicional com as novas demandas e práticas clínicas, de modo a incluir serviços e intervenções que demonstrem uma atualização frente aos desafios que a realidade apresenta (Dutra, 2013). Nessa perspectiva, novos espaços de atuação em dispositivos de saúde e atenção psicossocial são inseridos no contexto de atuação do psicólogo, necessitando deste uma postura criativa e condizente a realidade social em que se trabalha. Paparelli e Nogueira-Martins (2007) afirmam que desde a regulamentação da profissão, a Psicologia esteve muito aquém das necessidades sociais da população, o que tornou o psicólogo um agente dispensável em muitos serviços públicos. Urge, pois, uma formação que esteja sintonizada com as demandas sociais, dado que diversos aspectos sociais incorporam e requerem do psicólogo um posicionamento inovador, a partir de ajustes criativos. Com efeito, uma abertura a experiência de lidar com o algo novo, contrabalança o fato de um psicólogo não estar preparado para trabalhar com determinadas demandas que lhe são estranhas. Essa proposta é algo presente na formação do psicólogo humanista.

No que refere ao campo da Saúde Pública, a formação do psicólogo, sobretudo humanista, ainda se insere em 
uma lógica distanciada das necessidades públicas (Souza \& Cury, 2009). Embora exista, por parte das instituições de ensino superior, a exigência de que o psicólogo esteja sintonizado com as necessidades sociais, ainda é perceptível certo distanciamento da academia com esse campo de atuação. Uma superação disso estaria no comprometimento de uma prática compreensiva às demandas públicas; e na aquisição de habilidades para promover integração grupal em equipes multidisciplinares, colocando-se em diálogo com vários saberes distintos e complementares, formando vínculos e facilitando o contato comunitário por vias da experiência. Assim, torna-se importante o desenvolvimento de uma formação humanística voltada à construção de um olhar social no sentido teórico e prático, sendo a experiência de contato com o outro e consigo o elemento crucial para o enriquecimento do humanista em formação.

\section{Relação entre formador e formando:}

\section{horizontalidade e não saber}

O processo formativo em Psicologia tem como uma premissa a necessidade de o estudante se colocar à disposição da comunidade em serviços de atendimentos durante os estágios profissionalizantes. Os dispositivos tradicionais presentes nesses espaços formativos são as clínicas-escolas ou os serviços de psicologia aplicada que intermediam o contato entre estagiário e cliente/população. Nesses lugares, intensificam-se o contato entre supervisor e estagiário e a escolha da perspectiva teórica que mais apetecerá o estudante durante o seu preparo para o mercado de trabalho (Sá, Azevedo Junior \& Leite, 2010).

O supervisor é, frequentemente, colocado na posição daquele quem supostamente sabe, pela sua posição acadêmica e cobrança dos estagiários e da instituição. Logo, espera-se que o supervisor saiba mais que o estagiário. $\mathrm{O}$ questionamento sobre "como fazer" se torna algo presente e constante nesse tipo de relação. Entretanto, ao supervisor humanista cabe a responsabilidade de se colocar disponível para o estagiário, oferecendo-lhe um suporte distinto daquele quem supostamente sabe tudo e como proceder. Esse tipo de supervisão, em suma, proporciona um lugar de acolhimento diante da experiência do inusitado e do não saber sobre o outro (cliente). Conquanto o termo "supervisão" evoque, a partir de sua etimologia, a ideia de uma "visão superior", não devemos entender aquilo que legitima a posição do 
supervisor apenas como um transmissor e fiscalizador dos conhecimentos técnicos pertinentes às intervenções realizadas pelo estudante. Parte-se, pois, do pressuposto de que a experiência do estudante é o recurso mais importante para o entendimento de sua formação, a despeito da competência técnica e teórica do supervisor (Sá e outros, 2010).

Sousa e Cury (2009) apontam a importância dada ao vivido como uma característica da psicologia humanística. A resposta daquilo que nos acontece antes de uma reflexão e elaboração cognitiva é uma manifestação direta da experiência. A compreensão desta por parte do estagiário contribui para o modelo formativo humanista. Nessa perspectiva, a dimensão de abertura a experiência do outro, no processo de estágio, torna-se imprescindível para adentrar a realidade do cliente. Focar somente técnicas, protocolos e explicações teóricas para lidar com uma demanda seria, pois, insuficiente ante ao mencionado modelo. Logo,

[...] há uma inversão do enfoque até então vivenciado na universidade pelos estagiários: agora é a experiência que vai ser o ponto de abertura para a compreensão da teoria, uma vez que é a partir do encontro do estagiário com a pessoa que busca o serviço da clínica universitária que as teorias são pensadas. Esta inversão é muito importante para a vivência do estágio clínico [...], pois convida os alunos a pensar e se apropriar criticamente da sua formação, propiciando uma atitude fenomenológica com relação aos próprios conhecimentos adquiridos durante o percurso universitário e uma suspensão de juízo acerca da posição de verdade das teorias e técnicas integrantes da grade curricular do curso de Psicologia (Sá e outros, 2010, p. 138).

$\mathrm{O}$ enfoque que possibilita a formação humanista ocorre, sobretudo, mediante o encontro com o outro em todas as suas implicações, receios e potencialidades. Isso sobrepõe a crença de que somente técnicas bem aplicadas e explicações teóricas bem fundamentadas são suficientes para ajudar o sujeito em seu sofrimento.

As perspectivas humanistas e fenomenológicas, destarte, concebem a supervisão num ideal relacional mais horizontal entre formador e formando, pois não se concebe o supervisor como alguém que conheça mais dos casos atendidos que os seus estagiários. A formação perpassa a angústia de lidar com o não saber. $\mathrm{O}$ contato com a teoria é levado em consideração, mas sempre em uma via dialógica entre as experiências que estão 
compondo o estagiário e a sua apreensão teórica. O aprendizado ocorre pela via de sustentação de atitudes para com o outro e não, somente, por fundamentações teóricas e domínios técnicos (Sá e outros, 2010).

\section{Recursos formativos no referencial humanista: o plantão psicológico e a versão de sentido}

A clínica-escola é uma ponte entre a formação acadêmica e a prática profissional, independente da abordagem teórica ela se torna o meio pelo qual estudantes entram em contato com diversas pessoas, demandas sociais e problemas da comunidade. Dessa perspectiva, indica-se o plantão psicológico como umas das principais modalidades interventivas praticadas na perspectiva humanista. Criado no Brasil, nos anos de 1970-1980, o plantão psicológico é um serviço ofertado por profissionais que permanecem a disposição das pessoas que dele necessita, com um tempo pré-determinado e ininterrupto de disponibilidade para atender qualquer demanda que apareça,sem um tempo de duração prévio de atendimento ou número de sessões definidas. Enquanto prática, o plantão psicológico pode ser disponibilizado nas clínicas-escola e outros espaços de cuidados, como hospitais, CAPES, PSF's,
CRAS, CREAS etc. (Paparelli \& Nogueira-Martins, 2007).

No que concerne aos estágios, a prática em plantão psicológico tem sido importante para fornecer suporte àqueles que por possuir uma demanda emergencial necessitam de um pronto atendimento, sem passar por triagens ou marcações de consultas. Assim, o plantonista se coloca à disposição daquele que o procura. Embora não possua $\mathrm{o}$ intento de se configurar enquanto uma psicoterapia, seus fins são terapêuticos e englobam uma grande parcela de abertura e contato com outras pessoas desconhecidas e diferentes, em um período curto de tempo. O plantão psicológico procura, pois, responder a experiência (demanda) imediata do cliente em seu momento de sofrimento. Para isso, intensifica a abertura do plantonista para lidar com o inusitado e desconhecido, e a capacidade para adentrar a experiência do cliente, de modo a proporciona-lhe um contato e uma (re)elaboração de sentidos ante aquilo que o afeta (Breschigliari \& Jafelice, 2015).

O processo de formação através do plantão psicológico possibilita, também, uma aproximação dos estudantes com a comunidade e a realidade social que circunscrevem o serviço, ampliando a compreensão dos diversos universos experienciais ali presentes. Nessa 
perspectiva, permite um olhar mais apurado para o outro e, sobretudo, para si mesmo enquanto terapeuta, pois é um trabalho que requer, do estagiário, uma tomada de posição pessoal, ética, política, social e profissional (Paparelli \& Nogueira-Martins, 2007).

A Psicologia Humanista tem como prerrogativa formativa uma abertura para a experiência do outro através da captação dos sentidos da experiência. Ao adotar uma postura de não saber sobre o outro, o plantonista se depara com a complexidade do inusitado e com o manejo da alteridade (de si e do outro), deslocando-se de sua própria experiência com fins a adentrar a experiência do outro. Nesse sentido, o plantão psicológico é uma prática que radicaliza a mencionada prerrogativa em diversas localidades (Paparelli \& Nogueira-Martins, 2007). Salientamos que, atualmente, é possível observar serviços de plantão psicológico que utilizam outros referenciais psicológicos que não o humanista.

Para além do plantão psicológico, indicamos outro recurso formativo de referencial humanista, a saber, a versão de sentido, entendido "[...] como um relato livre, escrito ou falado, que não tem pretensão de ser um registro objetivo do que aconteceu, mas sim de ser uma reação viva a isso, como uma palavra primeira" (Maia e outros, 2012, p. 185). Ou seja, busca pela expressão da experiência do modo mais direto e espontâneo, retratado pelo próprio sujeito que a viveu.

A versão de sentido tem sido utilizada como um recurso para facilitar a relação supervisor e estagiário, tornando-se uma alternativa viável à apreensão da via experiencial do estudante. A versão de sentido na supervisão, basicamente, estabelece que após o atendimento o estudante em uma folha de papel, imprima suas impressões em relação ao encontro ocorrido, identificando o que sentiu, pensou e lembrou, demarcando o que mais lhe afetou. Esse recurso objetiva ampliar a experiência do estagiário em relação ao que acontece consigo na formação de atender o outro. Com isso, a supervisão se torna algo além de um espaço de aquisição técnica e aprendizado teórico e prático de uma postura terapêutica (Maia e outros, 2012). O uso da versão de sentido rompe, portanto, com uma lógica formativa tradicional de discussão de casos clínicos, pois se interessa mais em registrar os impactos experienciais que o encontro terapêutico gerou no estagiário, do que a sua leitura sobre o que aconteceu com o cliente e uma explicação técnica sobre o que o acometeu e o que foi feito durante o atendimento.

\section{Considerações Finais}


Este estudo objetivou analisar a produção de conhecimento sobre a formação do psicólogo humanista em artigos compilados a partir de uma revisão sistemática. Os resultados apontam para uma: hegemonia de textos publicados em um periódico de orientação humanista, fenomenológica e existencial; predominância de publicações no PePSIC; concentração de discussões voltadas para a área clínica; tendência para utilizar referenciais humanistas e fenomenológicos-existenciais para pesquisar e refletir empírica e teoricamente o tema da formação. Decorrentes desses estudos ponderamos quatro eixos temáticos concernentes à experiência formativa do psicólogo humanista, que discutiram: a tensão entre um modelo de formação técnica e uma proposta de formação experiencial; o entendimento da clínica como um lugar de formação pessoal e transformação social; a relação horizontal entre formador (supervisor) e formando (estagiário); o uso do plantão psicológico e da versão de sentido como recursos para a formação humanística. Consideramos que tais resultados e discussões respondem a pergunta lançada na introdução deste trabalho.

Com base nos artigos obtidos e lidos, considera-se que a temática da formação em Psicologia Humanista não tem sido explorada amplamente. Isso é percebido ante a amostra bibliográfica final de artigos compilados sobre esse tema. A partir disso, sentimos falta de mais resultados que possam incensar outras discussões.

A despeito disso, na contramão das técnicas e dos modelos teóricos enrijecidos em relação à formação profissional, a Psicologia Humanista se coloca como uma proposta fluída de contato consigo e com o outro, com um modelo formativo igualmente concebido por esse viés. Assim,

Entendemos que essa é a expressão do que seja a formação do psicólogo enquanto um processo de transformação: tirá-lo da f(ô)rma que despotencializa, e deixá-lo descobrirse, revelar-se e potencializar-se ao partir em busca da melhor forma possível para si, criando-se e recriando-se a cada momento na experiência compartilhada de transformar-se. Se estamos investindo na formação de um futuro profissional agente de transformação, precisamos repensar o quanto a graduação em Psicologia tem sido reprodutora de repetidores em série, formatadora de profissionais da repetição, legitimadores da lógica do sistema capitalista, dirigidos para a eficiência 
que o mercado de trabalhos espera deles (Soares, 2009, p. 155).

Concluímos com o indicativo da necessidade de mais estudos sobre a temática da formação do Psicólogo Humanista, sobretudo em ambientes extraacadêmicos, assim como sugerimos estudos sobre as implicações teóricas, técnicas e subjetivas que esse modelo formativo tem provocado em seus estudantes. O tema da formação se torna importante diante dos desafios oriundos do mercado de trabalho e das atuais demandas sociais e clínicas que requerem um posicionamento das diversas abordagens humanistas.

\section{Referências}

Breschigliari, J., \& Jafelice, G. (2015). Plantão Psicológico: ficções e reflexões. Psicologia: Ciência e Profissão, 35(1), 225-237. DOI: 10.1590/1982-3703000112014.

Carvalho, L., Alves, A., Passos, C., Lopes, F., Holanda, R., \& Moreira, V. (2015). A ética do cuidado e o encontro com o futuro no contexto de uma clínica-escola em Fortaleza. Revista da Abordagem Gestáltica, XXI(1), 01-12.

Costa, A., \& Zoltowski, A. (2014). Como escrever um artigo de revisão sistemática. InS. Koller., M. Couto., \& J. Hohendorff (Orgs.), Manual de produção científica (55-70). Porto Alegre: Penso, 2014.

Dutra, E. (2013). Formação do psicólogo clínico na perspectiva fenomenológico-existencial: dilemas e desafios em tempos de técnicas. Revista da Abordagem Gestáltica, XIX(2), 205-211.

Helou, F. (2015). Frederick Perls, vida e obra em busca da Gestalt-Terapia. São Paulo: Summus.

Maia, J., Freire, J., \& Oliveira, M. (2012). "Versando Sentidos" sobre o processo de aprendizagem em Gestalt-terapia. Revista da Abordagem Gestáltica, XVIII (2), 179187.

Packer, A., Cop, N., Luccisano, A., Ramalho, A., \& Spinak, E. (Orgs.). (2014). SciELO - 15 anos de acesso aberto e comunicação científica. Paris: UNESCO.

Paparelli, R., \& Nogueira-Martins, M. (2007). Psicólogos em formação: vivências e demandas em plantão psicológico. Psicologia: Ciência e Profissão, 27(1), 64-79. DOI: 10.1590/s1414-98932007000100006. 
Rogers, C. (1977). Psicoterapia e relações humanas - Volume 2: teoria e prática da terapia não diretiva. Belo Horizonte: Interlivros.

Rogers, C. (1983). Um jeito de ser. São Paulo: EPU.

Sá, R., Azevedo Junior, O., \& Leite, T. (2010). Reflexões fenomenológicas sobre a experiência de estágio e supervisão clínica em um serviço de psicologia aplicada universitário. Revista da Abordagem Gestáltica, XVI(2), 135-140.

Soares, L. (2009). A Gestalt-Terapia na universidade: da $\mathrm{f}(\hat{o}) \mathrm{rma}$ à boa forma. Estudos $e$ Pesquisas em Psicologia, 9(1),152-163. DOI: 10.12957/epp.2009.9141.

Society for Humanistic Psychology. Division 32. (2017). Disponível em: $<$ http://www.apadivisions.org/division-32/about/index.aspx>. Acesso em: 08 mai. 2017.

Sousa, V., \& Cury, V. (2009). Psicologia e atenção básica: vivências de estagiários na Estratégia de Saúde da Família. Ciência \& Saúde Coletiva, 14(1), 1429-1438. DOI: 10.1590/S1413-81232009000800016.

Taylor, E., \& Martin, F. (2001). Humanistic psychology at the crossroads. InK. Schneider., J. Bugental., \& J. Pierson (Eds.),The handbook of humanistic psychology: leading edges in theory research and practice (21-28). ThousandsOak, California: Sage. DOI: 10.4135/9781412976268.n2.

Yamamoto, O.; Costa, A. (Orgs). (2010). Escritos sobre a profissão de psicólogo no Brasil. Natal: EDUFRN.

\section{Os autores:}

Paulo Coelho Castelo Branco é professor adjunto I do Curso de Psicologia do Instituto Multidisciplinar em Saúde da Universidade Federal da Bahia. Doutor em Psicologia pela Universidade Federal de Minas Gerais. Coordenador do Núcleo de Estudos em Psicologia Humanista. E.mail: pauloccbranco@ gmail.com

Gabriel Nery Matos é graduando em Psicologia pela Universidade Federal da Bahia. Membro do Núcleo de Estudos em Psicologia Humanista. Bolsista de Iniciação Científica do Programa Permanecer/UFBA. E.mail: gabrielnerymatos95@gmail.com

Alexandre Gregório Silva Sampaio é graduando em Psicologia pela Universidade Federal da Bahia. Membro do Núcleo de Estudos em Psicologia Humanista. E.mail: alex.gregorio.111@ gmail.com

Bruna Rocha Amaral é graduanda em Psicologia pela Universidade Federal da Bahia. Membro do Núcleo de Estudos em Psicologia Humanista. E.mail: bruuhamaral7@gmail.com

Recebido em: 22/05/2017.

Aprovado em: 19/06/2017. 